\title{
Incidence of Deformation and Fracture of Twisted File Adaptive Instruments after Repeated Clinical Use
}

\author{
Gianluca Gambarini ${ }^{1}$, Lucila Piasecki², Dario Di Nardo ${ }^{1}$, Gabriele Miccoli ${ }^{1}$, Gianni Di Giorgio ${ }^{1}$, \\ Everdan Carneiro $^{3}$, Dina Al-Sudani ${ }^{4}$, Luca Testarelli ${ }^{1}$ \\ ${ }^{1}$ Department of Oral and Maxillo Facial Sciences, Sapienza University of Rome, Rome, Italy. \\ ${ }^{2}$ Department of Periodontics and Endodontics, University at Buffalo School of Dental Medicine, Buffalo, New York, USA. \\ ${ }^{3}$ Department of Endodontics, Pontifical Catholic University of Paranà, Curitiba, Paraná, Brazil. \\ ${ }^{4}$ Department of Restorative Dental Sciences, College of Dentistry, King Saud University, Riyadh, Saudi Arabia.
}

\author{
Corresponding Author: \\ Dario Di Nardo \\ Via Caserta, 6 - 00161 Roma \\ Italy \\ Phone: +39 3393935527 \\ Fax: +390683791592 \\ E-mail:dario_dinardo@hotmail.it
}

\begin{abstract}
Objectives: The aim of the present study was to investigate the incidence of deformation and fracture of twisted file adaptive nickel-titanium instruments after repeated clinical use and to identify and check whether the three instruments within the small/medium sequence showed similar or different visible signs of metal fatigue.

Material and Methods: One-hundred twenty twisted file adaptive (TFA) packs were collected after clinically used to prepare three molars and were inspected for deformations and fracture.

Results: The overall incidence of deformation was $22.2 \%$, which was not evenly distributed within the instruments: $15 \%$ for small/medium $(\mathrm{SM}) 1(\mathrm{n}=18), 38.33 \%$ for SM2 $(\mathrm{n}=46)$ and $13.33 \%$ for the SM3 instruments $(\mathrm{n}=16)$. The defect rate of SM2 instruments was statistically higher than the other two $(\mathrm{P}<0.001)$. The fracture rate was $0.83 \%(\mathrm{n}=3)$, being two SM2 instruments and one SM3.

Conclusions: It was observed a very low defect rate after clinical use of twisted file adaptive rotary instruments. The untwisting of flutes was significantly more frequent than fracture, which might act as prevention for breakage. The results highlight the fact that clinicians should be aware that instruments within a sequence might be differently subjected to intracanal stress.
\end{abstract}

Keywords: endodontics; nickel; root canal therapy; titanium.

Accepted for publication: 25 November 2016

To cite this article:

Gambarini G, Piasecki L, Di Nardo D, Miccoli G, Di Giorgio G, Carneiro E, Al-Sudani D, Testarelli L.

Incidence of Deformation and Fracture of Twisted File Adaptive Instruments after Repeated Clinical Use

J Oral Maxillofac Res 2016;7(4):e5

URL: http://www.ejomr.org/JOMR/archives/2016/4/e5/v7n4e5.pdf

doi: $10.5037 /$ jomr.2016.7405 


\section{INTRODUCTION}

The success of endodontic treatment is directly correlated to an efficient biomechanical preparation aiming to clean and disinfect the root canal system. The use of mechanized nickel-titanium (NiTi) files for root canal shaping is associated with well-centered preparations, reduced operator fatigue and less operatory time, but the file separation is still a major concern in clinical practice [1-5].

Reciprocating motions have been recently introduced as an alternative way of shaping root canals with $\mathrm{NiTi}$, aiming at reducing instrumentation stress. The basic concept is that when the two reciprocating angles are different, the resulting motion is a noncontinuous rotation. The partial rotation in one direction engages the NiTi instrument inside the canal, allowing cutting, debris removal and apical progression. The partial rotation in the opposite sense (usually with a significantly lower angle) promotes its disengagement and releases the stress. The safety is also increased by using cutting angles smaller than the elastic or fracture limit (deflection angle) of the instrument [1]. Whereas continuous rotation generates the accumulation of metal fatigue, the reciprocating motions promote alternating stress and release, therefore reducing both torsional and flexural stresses. Several studies clearly showed the increase in mechanical resistance of NiTi instruments used in reciprocation when compared to their use in continuous rotation [1-5].

The twisted file adaptive (TFA) system (Kerr Endodontics, Glendora, Orange, CA, USA) consist of a sequence of three NiTi instruments that are meant to be used with a specific reciprocating motion, given by the Elements Motor (Kerr Endodontics, Glendora, Orange, CA, USA). The TFA small/ medium (SM) shaping sequence consists of three NiTi instruments with the following tip sizes and tapers: SM1 (20.04), SM2 (25.06) and SM3 (35.04). According to the manufacturer, the TFA motion uses a range of reciprocating angles that automatically vary according to the detected intracanal stress (from $600^{\circ} / 0^{\circ}$ up to $370^{\circ} / 50^{\circ}$ ), aiming at optimizing efficacy and prevention of failures. This kinematic was reported to significantly increase in vitro instrument's resistance to fracture compared to the rotary motion, to reduce screwing-in effect $[\underline{6}, 7]$ and to reduce the amount of apically extruded debris []]. The TFA system also resulted in fewer dentinal cracks and higher cutting efficiency when compared to other reciprocating instruments $[9, \underline{10}]$. However, no data are reported about clinical resistance to breakage of TFA instruments.
Previous studies that investigated different brands of rotary NiTi instruments after clinical use suggested that the occurrence of defects is a multifactorial problem and can be affected by the number of uses, the experience of the operator, method of use, instrumentation technique, anatomical complexity of the root canals, design, diameter and taper of the instruments and manufacturing process [11-18]. Since different motions result in different instrumentation stresses, deformation and fracture rate may also be affected. However, to the best of our knowledge there is no information available about the incidence of defects in TFA instruments after repeated clinical use. Therefore, the aim of the present study was to investigate the incidence of deformation and fracture of twisted file adaptive nickel-titanium instruments after repeated clinical use and to identify and check whether the three instruments within the SM sequence showed similar or different visible signs of metal fatigue.

\section{MATERIAL AND METHODS}

A total of 120 TFA SM packs (360 NiTi instruments) were collected after clinical use over 15 months. Prior to use, all instruments were observed under stereomicroscope at original magnification x20 (Karl Kaps Gmbh, Asslar, Germany) to discard those with deformations or defects. Each set of TFA SM was assigned to prepare three molar cases ( 8 to 10 canals) by three endodontists (GG, GM, DDN). The case selection excluded teeth presenting immature apex, root fractures, previous endodontic treatment, extensive root resorption, C-shaped canals and dilacerated roots.

The root canal treatments were conducted under anaesthesia and rubber dam isolation. After coronal access, a mechanical glide path was created, by using the 0.02 stainless steel (SS) manual K-files (which are included in the SM package) attached to an M4 reciprocating $30^{\circ}-30^{\circ}$ hand-piece (M4 program available in the Elements Motor). The SS files ISO sizes 8,10 and 15 were used with the M4, until the $15 \mathrm{~K}$-file could be inserted into the canal without prebending or pressure. After the establishment of glide path, the sequence of three NiTi TFA instruments were used according to manufacturer's instruction, running with the non-editable TFA program available in the Elements Motor. All the instruments reached working length, progressing in a series of steps of 1 - $2 \mathrm{~mm}$. After each step, the instrument was retrieved from canal and cleaned to limit packing of debris inside flutes. Following manufacturer's instructions, 
if any sign of distortion or fracture was detected, the instrument was identified, discarded and replaced for a new one; being that the substitute instruments were not included in the data. Irrigation with 5\% sodium hypochlorite [19] was performed during all the shaping procedures. After completing the preparation of each molar case, the set of instruments was sterilized by autoclave and also identified to be used up to a maximum of 10 canals.

The length of each collected instrument was measured by using a digital caliper to a precision of $0.01 \mathrm{~mm}$, this aimed to determine if occurred any fracture that was not previously clinically detected. In the same way, they were visually inspected for plastic deformation under a stereomicroscope at original magnification x20 (Karl Kaps Gmbh, Asslar, Germany). The surfaces of fractured instruments were also viewed under a Scanning Electron Microscope (SEM) to evaluate the fracture mode. Data was statistically analysed using the SPSS 17.0 software (SPSS Incorporated, Chicago, IL, USA).

\section{Statistical analysis}

Data were described in terms of absolute and relative (percentage) frequencies. Chi-squared test was used to assess differences in frequency of defects among SM2 instruments and operators and to compare frequencies of fractures and unwinding. The significance level was set at $\mathrm{P}<0.05$.

\section{RESULTS}

A total of 352 molars were prepared (188 maxillary and 164 mandibular). Deformation of files after the use in the first molar was observed in 4 kits $(8$ instruments), and these files were no longer used to prepare more cases. The remaining 116 kits of TFA SM instruments were used to prepare a minimum of 8 canals, up to a maximum of 10 for each set of instruments. The incidence of instrument deformation (Figure 1) was 22.2\%, which was not evenly distributed within the three instruments of the sequence (Table 1). The defect rate of SM2 instruments was statistically higher than the other two $(\mathrm{P}<0.001)$. Of the 80 deformed instruments, $71(88.75 \%)$ were elongated and $9(11.25 \%)$ presented shortening of the flutes. There was no difference among the three operators regarding the percentage of incidence of defects (Chi-square test $\mathrm{P}>0.05$ ). Regarding the number of uses, in $53.75 \%$ of the cases the distortion was noted in the preparation of the third molar but with no statistically significant difference (Table 2).

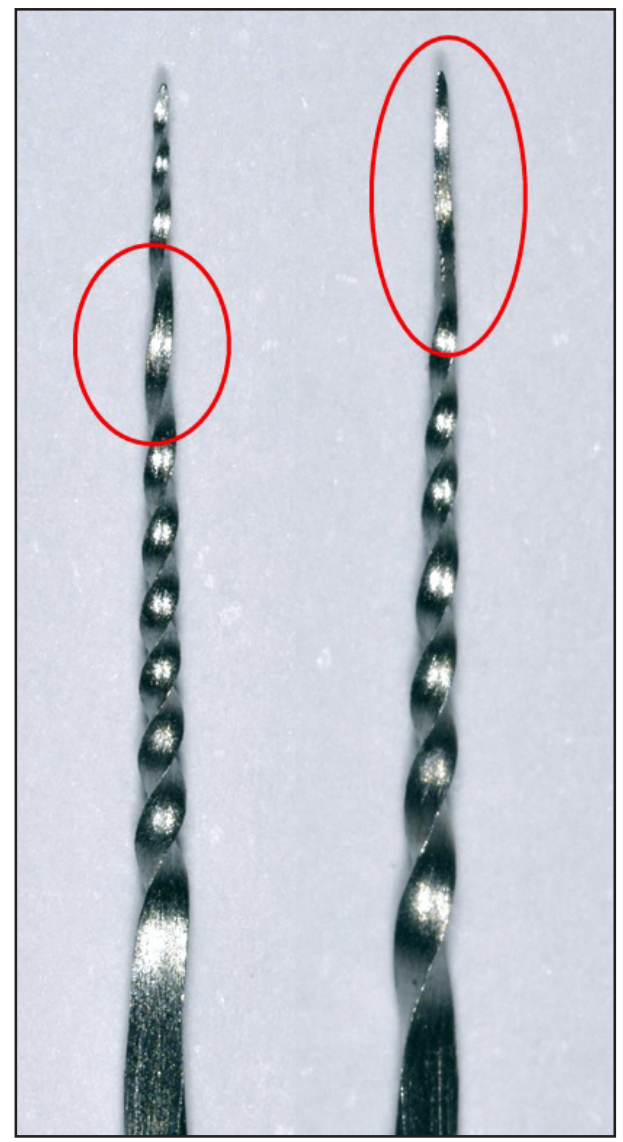

Figure 1. Example of plastic deformation (unwinding of flutes) of twisted file adaptive SM2 and SM3.

Table 1. Number and percentage of defects on twisted file adaptive (TFA) instruments

\begin{tabular}{c|c|c|c|c|c}
\hline \multirow{2}{*}{ Instrument } & \multirow{2}{*}{$\mathbf{N}$} & \multicolumn{2}{|c|}{ Deformation } & \multicolumn{2}{c}{ Fracture } \\
\cline { 3 - 6 } & & $\mathbf{n}$ & $\mathbf{\%}$ & $\mathbf{n}$ & $\mathbf{\%}$ \\
\hline SM1 & 120 & 18 & $15^{\mathrm{a}}$ & 0 & $0^{\mathrm{a}}$ \\
\hline SM2 & 120 & 46 & $38.33^{\mathrm{b}}$ & 2 & $1.66^{\mathrm{a}}$ \\
\hline SM3 & 120 & 16 & $13.33^{\mathrm{a}}$ & 1 & $0.8^{\mathrm{a}}$ \\
\hline
\end{tabular}

Different superscript letters indicate statistically significant difference within column.

$\mathrm{N}=$ number of TFA instruments used; $\mathrm{n}=$ number of deformations or fractures observed; $\mathrm{SM}=$ small $/$ medium.

Table 2. Incidence of defects on twisted file adaptive instruments according to the number of uses

\begin{tabular}{l|c|c|c|c|c|c|c|c|c}
\hline \multirow{2}{*}{ Instrument } & \multirow{2}{*}{$\mathbf{N}$} & \multicolumn{2}{|c|}{$\mathbf{1}^{\text {st }}$ case } & \multicolumn{2}{|c|}{$\mathbf{2}^{\text {nd }}$ case } & \multicolumn{2}{c|}{$3^{\text {rd }}$ case } & \multicolumn{2}{c}{ Unknown } \\
\cline { 3 - 10 } & & $\mathbf{n}$ & $\mathbf{\%}$ & $\mathbf{n}$ & $\mathbf{\%}$ & $\mathbf{n}$ & $\mathbf{\%}$ & $\mathbf{n}$ & $\mathbf{\%}$ \\
\hline Deformation & 80 & 8 & $10^{\mathrm{a}}$ & 26 & $32.5^{\mathrm{a}}$ & 43 & $53.75^{\mathrm{a}}$ & 3 & $3.75^{\mathrm{a}}$ \\
\hline Fracture & 3 & 0 & $0^{\mathrm{a}}$ & 0 & $0^{\mathrm{a}}$ & 3 & $100^{\mathrm{b}}$ & 0 & $0^{\mathrm{a}}$ \\
\hline
\end{tabular}

Different superscript letters indicate statistically significant difference within row.

$\mathrm{N}=$ total number of deformations and fractures observed; $\mathrm{n}=$ number of deformations and fractures observed after each case. 


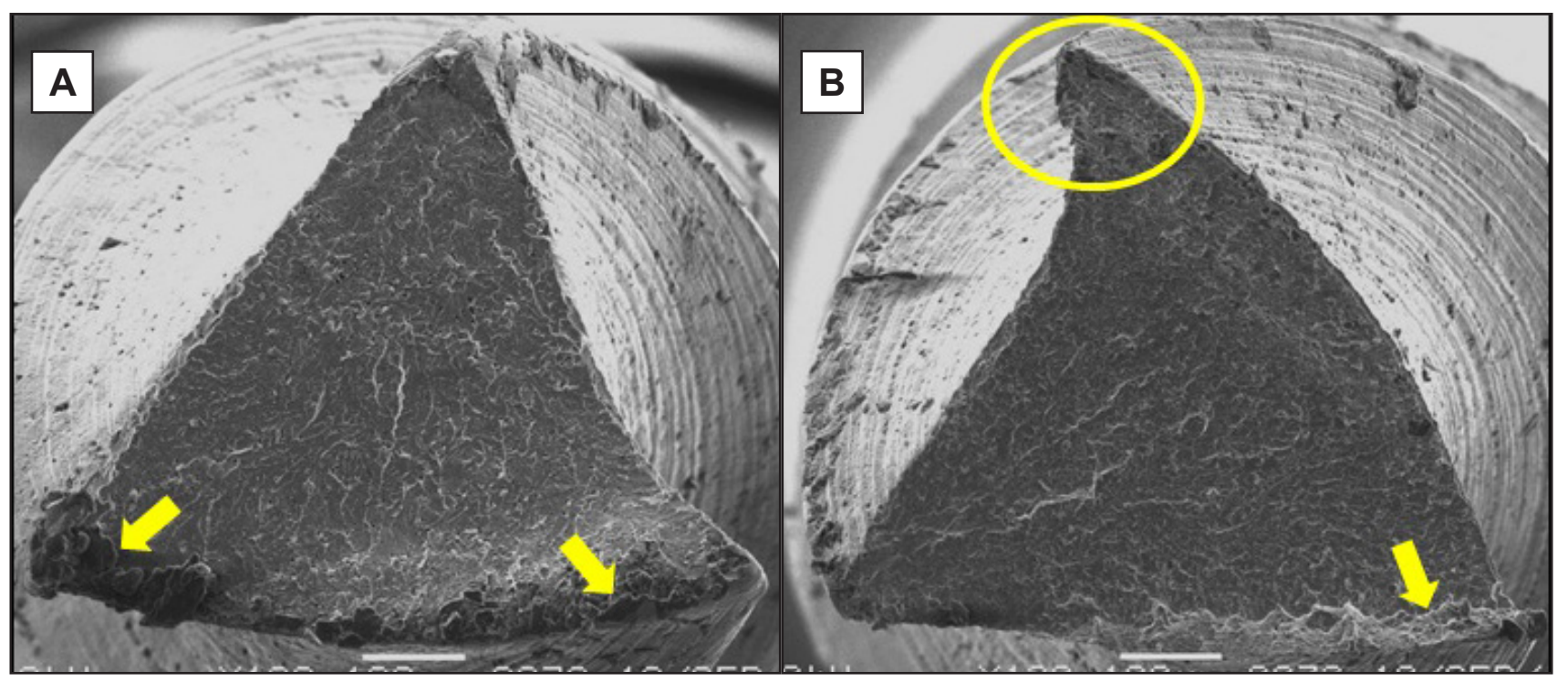

Figure 2. Fractographic analysis of twisted file adaptive broken instruments showed signs of flexural fatigue (indicated by the arrows) and in some specimens also torsional fatigue (indicated by the circle).

$\mathrm{A}=\mathrm{SM} 3$ instrument; $\mathrm{B}=\mathrm{SM} 2$ instrument.

There was a difference in the site of deformation among instruments: while most of SM2 deformed at middle part, the SM1 and SM3 deformed close to the tip.

During the clinical procedures, three instruments fractured (two SM2 and one SM3). The fracture was confirmed by the later inspection and measurement of the files. The overall fracture rate was $0.8 \%$, significantly lower than the incidence of unwiding $(\mathrm{P}<0.0001)$. All the fractures occurred after the third clinical case. SEM fractographic analysis of the broken instruments showed signs of both torsional and flexural fatigue (Figure 2).

\section{DISCUSSION}

Previous studies have shown that the clinical fracture incidence of NiTi instruments varied from $0.3 \%$ to $23 \%$ among different clinics worldwide [11$\underline{16}, \underline{18}, \underline{20}, 21]$. The overall fracture incidence of TFA recorded in the present study $(0.8 \%)$ is close to the lowest values of the reported range. This low fracture rate could be related to different factors, including the motion, the design of the instruments and its manufacturing process [1-3,7]. Gambarini et al. [22] showed that the twisting process of TF instruments resulted in an increased resistance to breakage compared to instruments produced by grinding.

It is known that intracanal file breakage is more likely to occur in severe, abrupt curvatures or S-shaped canals $[12,23,24]$. The fact that file separation occurs mainly in molars, when compared to other tooth types, have been correlated not only to the anatomical complexity but also to its clinical accessibility [12]. However, clinically it is not possible to standardize the anatomy of the teeth or the difficulty of the cases (e.g. the canal diameter, the curvature angles, dentin hardness). Most of previous clinical studies that reported low fracture rates of different brands of instruments, have included all dental groups $[12,15,18,21]$. Nevertheless, in the present study it was set a level of difficulty by including only molar cases. These tooth type was selected because TFA SM sequence is recommended for small and/or curved canals, which are more likely found in molars. Even tough, the incidence of fracture in the present study was similar to that reported in studies that included also anterior teeth and premolars $[\underline{12}, \underline{15}, \underline{18}, \underline{21}]$.

The deformations rate of NiTi files reported in the literature vary from 0.3 to $28 \%$, which commonly is slightly lower or similar to the fracture rate [1114, 16-21]. In the present investigation, the incidence of defects was significantly higher $(22.2 \%)$ than the fractures rate $(0.8 \%)$. It has been suggested that the design of the instrument play a major role in determining resistance to intracanal stress $[\underline{12}, \underline{14}]$. However, for the TFA instruments, the manufacturing process might also explain the greater occurrence of deformations. The combination of heat treatment and twisting process leads the TFA instruments to present a clinical behaviour different from the majority of grounded NiTi rotary instruments. Likewise stainless steel files, when subjected to excessive intracanal stress, they tend to show a greater amount of plastic deformation (unwinding of flutes) before breakage (Figure 1). This propensity for unwinding flutes can be considered as a safety feature $[\underline{12}, \underline{13}, \underline{23}]$ 
that allows clinicians to visualize metal fatigue and avoid overuse. The plastic deformation of the files in the present investigation could be detected clinically in the majority of cases $(96.25 \%)$. In four cases, it was observed plastic deformation during the first use of the TFA set, probably related to the complex anatomy of the teeth. By showing clinical evidence of metal fatigue, these instruments allow the clinician to discard the deformed instruments on a rationale base [17]. The majority of grounded NiTi rotary instruments usually undergo to unexpected fracture without any previous signs of metal fatigue or unwinding of flutes $[12,13,17,23]$.

The present study also confirmed previous ones showing that instruments within a sequence are subjected to different intracanal stresses, due to different dimensions and different blade engagement $[\underline{12}, \underline{25}, \underline{26}]$. Among the three TFA instruments, the first and third one (SM1 and SM3) presented lesser deformation/fracture rates. Although unwinding was observed in $15 \%$ of SM1, none of the 120 instruments fractured. This finding is probably related not only to the instrument smaller size, but also to the previous establishment of an adequate glide path, up to a number $15 \mathrm{~K}$-file [27,28]. Similarly, the SM3 is subjected to stress only in the last $4 \mathrm{~mm}$, which explains their low deformation rate and only one fractured file.

The SM2 presented the highest deformation rate $(38.33 \%)$ and two fractures. This is correlated to the dimensions, because this file increased both taper and size preparation, being more subjected to intracanal stress. These results showed SM2 to be the most critical instruments inside this sequence, thus requiring a more delicate and cautious approach, to minimize blade engagement and tip lock. Clinical studies showed that among the ProTaper sequence, the S1 instrument corresponded to $62 \%$ of all separated files [12] while for K3 instruments, the defect rates were significantly higher for the tapers 0.06 and 0.04 [15]. Accordingly, the present findings highlight that to provide useful information, studies about fracture and deformation rates of NiTi instruments should be more detailed and analyse their behaviour inside a sequence.

The separation of rotary NiTi instruments has been mainly associated to flexural stress $[\underline{12}, \underline{13}, \underline{15}, \underline{26}]$.
Fractographic analysis of TFA SM2 and SM3 broken instruments showed signs of both torsional and flexural fatigue (Figure 2). This fact might be also related the influence of the kinematics (reciprocation) on the response to mechanical stresses [29, $\underline{30}]$. This assumption is corroborated by a recent study that evaluated the incidence of defects after clinical use of WaveOne and found that these reciprocating instruments fractured by shear stress [18].

The evaluation of the other two commercially available reciprocating instruments also showed a very low incidence of fracture and deformation after clinical use, respectively $0.47 \%$ and $0.35 \%$ for Reciproc [20], and $0.5 \%$ and $9.6 \%$ for Waveone [18]. However, it is important to notice this low fracture rate of Reciproc and WaveOne are also related to the fact that, according to manufaturers' instructions, both are single-use system while TFA is intended for multiple uses. The repeated use of NiTi files (more than 8 times), have been reported to increase significantly the separation rate $[\underline{12}, \underline{28}]$. In the present study despite the repeated clinical use, only 3 instruments fractured $(0.8 \%)$ which are probably correlated to the combination of TFA instruments with the adaptive motion $[\underline{7}, \underline{30}]$.

\section{CONCLUSIONS}

Therefore, it was concluded that twisted file adaptive instruments presented a very low fracture rate and a high incidence of plastic deformation after repeated clinical use. Since the small/medium 2 instruments presented significantly more deformation, the clinical relevance of the present study lies in demonstrating that instruments within a sequence might be differently subjected to intracanal stress and clinicians must understand the different behaviour and perform instrumentation accordingly.

\section{ACKNOWLEDGMENTS AND DISCLOSURE STATEMENTS}

The authors declare that there are no financial or other conflicts of interest related to this publication.

\section{REFERENCES}

1. Gambarini G, Rubini AG, Al Sudani D, Gergi R, Culla A, De Angelis F, Di Carlo S, Pompa G, Osta N, Testarelli L. Influence of different angles of reciprocation on the cyclic fatigue of nickel-titanium endodontic instruments. J Endod. 2012 Oct;38(10):1408-11. [Medline: 22980189] [doi: 10.1016/j.joen.2012.05.019] 
2. Pedullà E, Grande NM, Plotino G, Gambarini G, Rapisarda E. Influence of continuous or reciprocating motion on cyclic fatigue resistance of 4 different nickel-titanium rotary instruments. J Endod. 2013 Feb;39(2):258-61. [Medline: 23321241] [doi: 10.1016/i.joen.2012.10.025]

3. Gambarini G, Gergi R, Naaman A, Osta N, Al Sudani D. Cyclic fatigue analysis of twisted file rotary NiTi instruments used in reciprocating motion. Int Endod J. 2012 Sep;45(9):802-6. [Medline: 22429241] [doi: 10.1111/j.1365-2591.2012.02036.x]

4. Castelló-Escrivá R, Alegre-Domingo T, Faus-Matoses V, Román-Richon S, Faus-Llácer VJ. In vitro comparison of cyclic fatigue resistance of ProTaper, WaveOne, and Twisted Files. J Endod. 2012 Nov;38(11):1521-4. [Medline: 23063228] [doi: 10.1016/i.joen.2012.07.010]

5. Çapar ID, Arslan H. A review of instrumentation kinematics of engine-driven nickel-titanium instruments. Int Endod J. 2016 Feb;49(2):119-35. [Medline: 25630977] [doi: 10.1111/iej.12432]

6. Gambarini G, Glassman G. TF adaptive: a novel approach to nickel-titanium instrumentation. Oral Health. 2013 May;7(2):22-30. [URL: http://www.oralhealthgroup.com]

7. Gambarini G, Glassman G. In vitro analysis of efficiency and safety of a new motion for endodontic instrumentation: TF Adaptive. Roots 2013(9)3:12-5. [URL: http://oemus.com/publication/roots/]

8. Capar ID, Arslan H, Akcay M, Ertas H. An in vitro comparison of apically extruded debris and instrumentation times with ProTaper Universal, ProTaper Next, Twisted File Adaptive, and HyFlex instruments. J Endod. 2014 Oct;40(10): 1638-41. [Medline: 25260737] [doi: 10.1016/j.joen.2014.04.004]

9. Karataş E, Gündüz HA, Kırıcı DÖ, Arslan H, Topçu MÇ, Yeter KY. Dentinal crack formation during root canal preparations by the twisted file adaptive, ProTaper Next, ProTaper Universal, and WaveOne instruments. J Endod. 2015 Feb;41(2):261-4. [Medline: 25476974] [doi: 10.1016/j.joen.2014.10.019]

10. Tocci L, Plotino G, Al-Sudani D, Rubini AG, Sannino G, Piasecki L, Putortì E, Testarelli L, Gambarini G. Cutting efficiency of instruments with different movements: a comparative study. J Oral Maxillofac Res. 2015 Mar 30;6(1):e6. [Medline: 25937877] [PMC free article: 4414237] [doi: 10.5037/jomr.2015.6106]

11. Sattapan B, Nervo GJ, Palamara JE, Messer HH. Defects in rotary nickel-titanium files after clinical use. J Endod. 2000 Mar;26(3):161-5. [Medline: 11199711] [doi: 10.1097/00004770-200003000-00008]

12. Shen Y, Cheung GS, Bian Z, Peng B. Comparison of defects in ProFile and ProTaper systems after clinical use. J Endod. 2006 Jan;32(1):61-5. [Medline: 16410072] [doi: 10.1016/j.joen.2005.10.017]

13. Inan U, Gonulol N. Deformation and fracture of Mtwo rotary nickel-titanium instruments after clinical use. J Endod. 2009 Oct;35(10):1396-9. [Medline: 19801238] [doi: 10.1016/i.joen.2009.06.014]

14. Parashos P, Gordon I, Messer HH. Factors influencing defects of rotary nickel-titanium endodontic instruments after clinical use. J Endod. 2004 Oct;30(10):722-5. [Medline: 15448468] [doi: 10.1097/01.DON.0000129963.42882.C9]

15. Shen SM, Deng M, Wang PP, Chen XM, Zheng LW, Li HL. Deformation and fracture of K3 rotary nickel-titanium endodontic instruments after clinical use. Int Endod J. 2016 Nov;49(11):1088-1094. [Medline: 26466821] [doi: $10.1111 /$ iej.12561]

16. Shen Y, Coil JM, Haapasalo M. Defects in nickel-titanium instruments after clinical use. Part 3: a 4-year retrospective study from an undergraduate clinic. J Endod. 2009 Feb;35(2):193-6. [Medline: 19166771] [doi: 10.1016/j.joen.2008.11.003]

17. Shen Y, Haapasalo M, Cheung GS, Peng B. Defects in nickel-titanium instruments after clinical use. Part 1: Relationship between observed imperfections and factors leading to such defects in a cohort study. J Endod 2009;35:129-32. [Medline: 19084142] [doi: 10.1016/j.joen.2008.10.014]

18. Shen Y, Haapasalo M, Cheung GS, Peng B. Defects in nickel-titanium instruments after clinical use. Part 1: Relationship between observed imperfections and factors leading to such defects in a cohort study. J Endod. 2009 Jan;35(1):129-32. [Medline: 26654140] [doi: 10.1016/i.joen.2015.10.008]

19. Gambarini G, De Luca M, Gerosa R. Chemical stability of heated sodium hypochlorite endodontic irrigants. J Endod. 1998 Jun;24(6):432-4. [Medline: 9693589] [doi: 10.1016/S0099-2399(98)80027-7]

20. Alapati SB, Brantley WA, Svec TA, Powers JM, Nusstein JM, Daehn GS. SEM observations of nickel-titanium rotary endodontic instruments that fractured during clinical Use. J Endod. 2005 Jan;31(1):40-3. [Medline: 15614004] [doi: 10.1097/01.DON.0000132301.87637.4A]

21. Plotino G, Grande NM, Porciani PF. Deformation and fracture incidence of Reciproc instruments: a clinical evaluation. Int Endod J. 2015 Feb;48(2):199-205. [Medline: 24754602] [doi: 10.1111/iej.12302]

22. Gambarini G, Grande NM, Plotino G, Somma F, Garala M, De Luca M, Testarelli L. Fatigue resistance of enginedriven rotary nickel-titanium instruments produced by new manufacturing methods. J Endod. 2008 Aug;34(8):1003-5. [Medline: 18634935] [doi: 10.1016/i.joen.2008.05.007]

23. Ankrum MT, Hartwell GR, Truitt JE. K3 Endo, ProTaper, and ProFile systems: breakage and distortion in severely curved roots of molars. J Endod. 2004 Apr;30(4):234-7. [Medline: 15085054] [doi: 10.1097/00004770-200404000-00013]

24. Al-Sudani D, Grande NM, Plotino G, Pompa G, Di Carlo S, Testarelli L, Gambarini G. Cyclic fatigue of nickel-titanium rotary instruments in a double (S-shaped) simulated curvature. J Endod. 2012 Jul;38(7):987-9. [Medline: 22703666] [doi: 10.1016/i.joen.2012.03.025] 
25. Gambarini G, Plotino G, Piasecki L, Al-Sudani D, Testarelli L, Sannino G. Deformations and cyclic fatigue resistance of nickel-titanium instruments inside a sequence. Ann Stomatol (Roma). 2015 May 18;6(1):6-9. [Medline: 26161246] [PMC free article: 4475905] [doi: 10.11138/ads/2015.6.1.006]

26. Ullmann CJ, Peters OA. Effect of cyclic fatigue on static fracture loads in ProTaper nickel-titanium rotary instruments. J Endod. 2005 Mar;31(3):183-6. [Medline: 15735465] [doi: 10.1097/01.don.0000137641.87125.8f]

27. Berutti E, Negro AR, Lendini M, Pasqualini D. Influence of manual preflaring and torque on the failure rate of ProTaper rotary instruments. J Endod. 2004 Apr;30(4):228-30. [Medline: 15085052] [doi: 10.1097/00004770-200404000-00011]

28. Pati-o PV, Biedma BM, Liébana CR, Cantatore G, Bahillo JG. The influence of a manual glide path on the separation rate of NiTi rotary instruments. J Endod. 2005 Feb;31(2):114-6. [Medline: 15671822] [doi: 10.1097/01.don.0000136209.28647.13]

29. Cheung GS, Darvell BW. Fatigue testing of a NiTi rotary instrument. Part 2: Fractographic analysis. Int Endod J. 2007 Aug;40(8):619-25. [Medline: 17511786] [doi: 10.1111/j.1365-2591.2007.01256.x]

30. Higuera O, Plotino G, Tocci L, Carrillo G, Gambarini G, Jaramillo DE. Cyclic fatigue resistance of 3 different nickel-titanium reciprocating instruments in artificial canals. J Endod. 2015 Jun;41(6):913-5. [Medline: 25771139] [doi: 10.1016/j.joen.2015.01.023]

\section{To cite this article:}

Gambarini G, Piasecki L, Di Nardo D, Miccoli G, Di Giorgio G, Carneiro E, Al-Sudani D, Testarelli L.

Incidence of Deformation and Fracture of Twisted File Adaptive Instruments after Repeated Clinical Use

J Oral Maxillofac Res 2016;7(4):e5

URL: http://www.ejomr.org/JOMR/archives/2016/4/e5/v7n4e5.pdf

doi: $10.5037 /$ jomr.2016.7405

Copyright (C) Gambarini G, Piasecki L, Di Nardo D, Miccoli G, Di Giorgio G, Carneiro E, Al-Sudani D, Testarelli L. Published in the JOURNAL OF ORAL \& MAXILLOFACIAL RESEARCH (http://www.ejomr.org), 28 December 2016. This is an open-access article, first published in the JOURNAL OF ORAL \& MAXILLOFACIAL RESEARCH, distributed under the terms of the Creative Commons Attribution-Noncommercial-No Derivative Works 3.0 Unported License, which permits unrestricted non-commercial use, distribution, and reproduction in any medium, provided the original work and is properly cited. The copyright, license information and link to the original publication on (http://www.ejomr.org) must be included. 